\title{
Treatment of Ruptured Vertebral Artery Dissecting Aneurysms
}

\section{A Short Report}

\author{
OSAMU HAMASAKI, FUSAO IKAWA, TOSHIKAZU HIDAKA, \\ YASUHARU KUROKAWA, USHIO YONEZAWA \\ Department of Neurosurgery, Shimane Prefectural Central Hospital; Izumo, Japan
}

Key words: vertebral artery, dissecting aneurysm, subarachnoid hemorrhage, internal endovascular trapping, medullary infarction

\section{Summary}

We evaluated the outcomes of endovascular or surgical treatment of ruptured vertebral artery dissecting aneurysms (VADAs), and investigated the relations between treatment complications and the development and location of the posterior inferior cerebellar artery (PICA).

We treated 14 patients (12 men, two women; mean age, 56.2 years) with ruptured VADAs between March 1999 and June 2012 at our hospital. Six and eight patients had Hunt and Hess grades 1-3 and 4-5, respectively.

Twelve patients underwent internal endovascular trapping, one underwent proximal endovascular occlusion alone, and one underwent proximal endovascular occlusion in the acute stage and occipital artery (OA)-PICA anastomosis and surgical trapping in the chronic stage. The types of VADA based on their location relative to the ipsilateral PICA were distal, PICA-involved, and non-PICA in nine, two, and three patients, respectively. The types of PICA based on their development and location were bilateral anterior inferior cerebellar artery (AICA)-PICA, ipsilateral AICA-PICA, extradural, and intradural type in one, two, two, and nine patients, respectively. Two patients with high anatomical risk developed medullary infarction, but their midterm outcomes were better than in previous reports. The modified Rankin scale indicated grades 0-2, 3-5, and 6 in eight, three, and three patients, respectively.

A good outcome is often obtained in the treatment of ruptured VADA using internal endovas- cular trapping, except in the PICA-involved type, even with high-grade subarachnoid hemorrhage. Treatment of the PICA-involved type is controversial. The anatomical location and development of PICA may be predicted by complications with postoperative medullary infarction.

\section{Introduction}

Previous reports on subarachnoid hemorrhage $(\mathrm{SAH})$ patients with ruptured vertebral artery dissecting aneurysms (VADAs) have emphasized a high incidence of rebleeding and high mortality rate at the time of rebleeding ${ }^{1,2}$. Although ruptured VADAs have been treated by craniotomy with clipping or trapping, internal endovascular trapping has become the firstline therapy because of its minimal invasiveness after diagnostic angiography ${ }^{3-8}$. Recent reports $7,9,10$ indicated that aggressive treatment should be considered for patients with VADA and high-grade SAH, but postoperative medullary or cerebellar infarction have been reported as complications of internal coil trapping ${ }^{3-5}$. Knowledge regarding the roles of pre- and post-posterior inferior cerebellar artery (PICA) segments of the intradural vertebral artery in pontine vascularization is therefore necessary, and this anatomy should even be envisaged to anticipate the risk of lateral ischemia after endovascular treatment. Anatomical studies have shown that perforating vessels arising from the PICA or proximal vertebral artery (VA) are responsible for vascularization of the 
posterior surface of the medulla oblongata. A lateral medullary infarction may occur if the artery is compromised ${ }^{11}$. The anatomical variations of these perforators largely depend on the development of the PICA and the location of the PICA origin ${ }^{11}$. If the PICA emerges from the common trunk of the AICA-PICA coming from the basilar artery, it does not give rise to perforating arteries or a lateral spinal artery on the lateral surface of the brainstem but supplies blood to part of the ipsilateral cerebellar hemisphere. If the PICA arises extradurally at $\mathrm{C} 1$, it does not give rise to perforating arteries for the lateral surface of the brainstem, but gives pial branches for the posterior surface of the medulla oblongata and is always the origin of the lateral spinal artery. If the PICA emerges in the intradural VA, it is the source of the perforating arteries for the lateral surface of the brainstem and of blood supply to the ipsilateral cerebellum. This study was performed to evaluate the outcome of endovascular or surgical treatment of ruptured VADA, and to investigate the relations between treatment complications and the development and location of the PICA.

\section{Materials and Methods}

\section{Patient Selection}

We treated 14 patients with ruptured VADAs between March 1999 and June 2012 in our hospital. The inclusion criteria for this study were as follows: the patient had undergone surgical or endovascular treatment for ruptured VADA, the patient's SAH was identified by CT, and the patient's diagnosis of VADA was rendered by cerebral angiography ${ }^{12}$. Another three patients died before treatment. Cases involving the basilar artery or traumatic VADA were excluded. The study population consisted of 12 men and two women with a mean age of 56.2 years (range: 43-69 years). Hunt and Hess grades just prior to treatment were grade 1 in one patient, grade 2 in two patients, grade 3 in three patients, grade 4 in two patients, and grade 5 in six patients. The locations of VADAs relative to the ipsilateral PICA were defined according to the criteria described previously by Iihara et al. ${ }^{4}$ VADAs on the distal side of the PICA were defined as distal type, those on the proximal side as proximal type, those in the PICA arising from a lesion as PICA-involved type, and the absence of angiographically rec- ognized ipsilateral PICA as non-PICA type. The development and location of the PICA were classified into three types: AICA-PICA coming from the basilar artery as AICA-PICA type, arising extradurally at $\mathrm{C} 1$ as extradural type, and emerging in the intradural vertebral artery as intradural type.

\section{Treatment}

To control the intracranial pressure and washout of subarachnoid hematomas, the patients underwent lumbar or ventricular drainage before commencement of endovascular treatment. Endovascular treatments were performed as soon as possible after admission. The timing of endovascular treatment after onset was within 24 hours in all 14 patients. Local anesthesia and sedation were administered to almost all patients requiring intubation for occlusion of the respiratory tract. After confirming hemostasis at the puncture site, systemic heparinization was started to maintain the activated clotting time at approximately twice the control value. Heparinization was stopped at the end of the procedure. Coil embolization of the dissecting aneurysm itself (i.e., internal trapping) was considered the primary endovascular strategy for acute stage of ruptured VADAs. However, if this procedure was not appropriate for preservation of the ipsilateral PICA or could not be performed for technical reasons, coil embolization of the normal vertebral artery proximally close to the dissecting aneurysm (i.e., proximal endovascular occlusion) was performed. In addition, in chronic stage, if the patient's general condition was good, a surgical procedure of OA to PICA anastomosis and trapping was performed under general anesthesia to prevent cerebellar infarction.

Our standard technique was as follows. A 7 Fr Patlive guiding catheter (Clinical Supply, Gifu, Japan) with a balloon was placed in the treated VA via the femoral artery. A single excelsior SL-10 microcatheter (Stryker, Kalamazoo, MI, USA) was advanced distal to the VADA and coil embolization was performed at the proximal end of VADA with balloon inflation. During coiling of the ipsilateral vertebral artery on the non-dominant side, a 7 Fr balloon guiding catheter was inflated to prevent rebleeding, coil migration, and thromboembolism. The main coils used were Guglielmi detachable coils and Matrix 2 detachable coils 

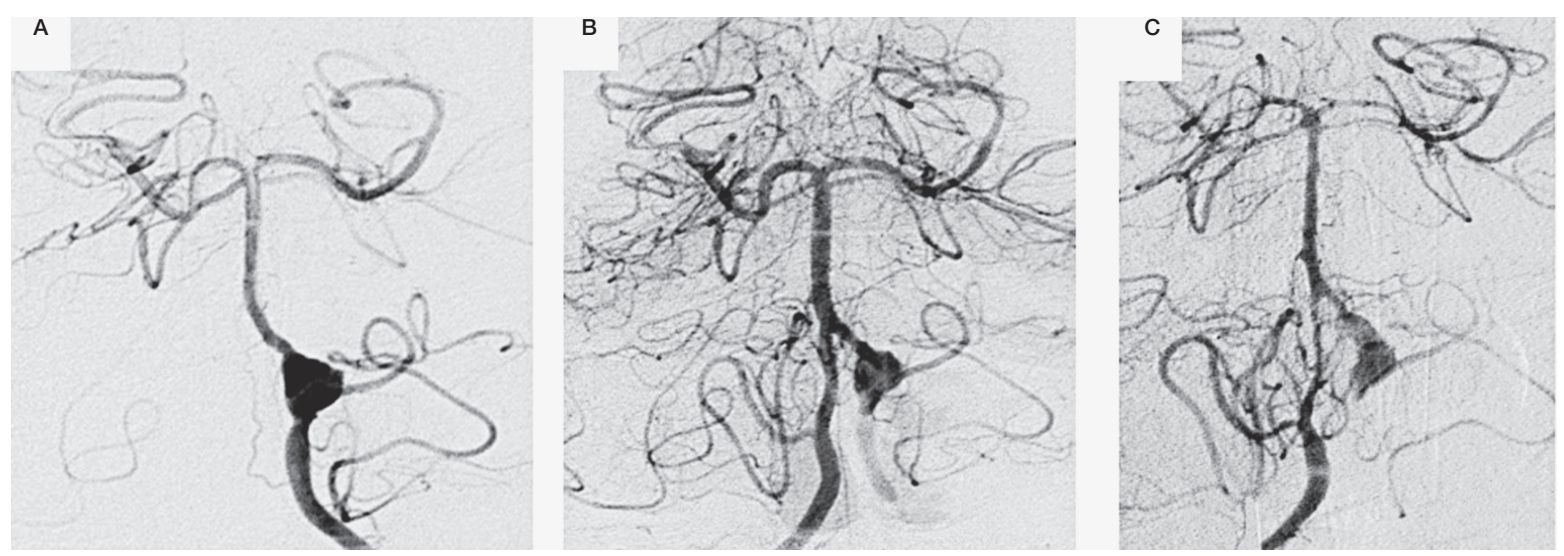

Figure 1 A) DSA revealed left VADA involving PICA origin. B) Proximal occlusion was performed. C) Severe vasospasm developed.
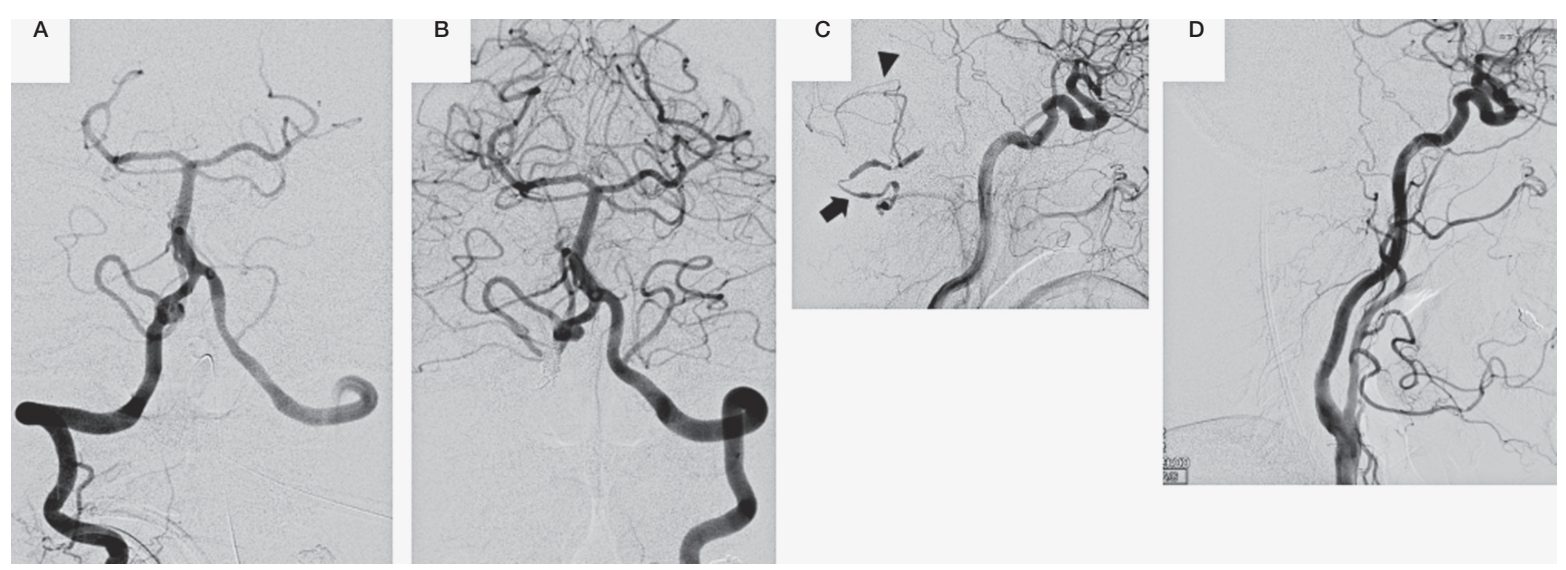

Figure 2 A) DSA revealed right VADA involving PICA origin. B) Proximal occlusion was performed. C) OA (arrow)-PICA (arrowhead) anastomosis and surgical trapping were performed. D) The patient developed asymptomatic occlusion of the bypass one month after bypass surgery.

(Stryker, Kalmazoo, MI, USA), and Electro Detach coils (Kaneka Medix Corporation, Osaka, Japan). After the procedure, medical management (hypertensive, hypervolemic, and hemodilution therapy) for vasospasm was performed. Cilostazol (200 $\mathrm{mg}$ ) and Atorvastatin $(5 \mathrm{mg})$ was given on the day after treatment and continued for two weeks. Follow-up evaluations with MRI were performed between March 1999 and October 2012.

\section{Results}

The types of VADA based on their location relative to the ipsilateral PICA were distal, PICA-involved, and non-PICA in nine, two, and three patients, respectively. The types of PICA based on their development and location were bilateral AICA-PICA, ipsilateral AICA-PICA, extradural, and intradural type in one, two, two, and nine patients, respectively. Among 14 patients in our series, 12 underwent internal endovascular trapping, one underwent proximal endovascular occlusion alone, and one underwent proximal endovascular occlusion in the acute stage and OA-PICA anastomosis and surgical trapping in the chronic stage (Table 1).

In our series, there were eight complications in the perioperative period: two patients developed rebleeding during the endovascular procedure, four patients developed symptomatic medullary or cerebellar infarction, one patient suffered recanalization of the VADA seven days after the first endovascular treatment, and one patient with OA-PICA anastomosis on chronic 
Table 1 Summary of 14 patients who underwent treatment of ruptured vertebral artery dissecting aneurysm

\begin{tabular}{|c|c|c|c|c|c|c|c|c|}
\hline $\begin{array}{l}\text { Patient } \\
\text { No. }\end{array}$ & $\begin{array}{l}\text { Age (yrs), } \\
\text { Sex }\end{array}$ & $\begin{array}{l}\mathbf{H} \& \mathbf{H} \\
\text { grade }\end{array}$ & $\begin{array}{l}\text { VADA } \\
\text { location }\end{array}$ & $\begin{array}{l}\text { PICA } \\
\text { development } \\
\text { and location }\end{array}$ & Treatment & $\begin{array}{l}\text { Perioperative } \\
\text { complication }\end{array}$ & $\begin{array}{l}\text { mRS on } \\
\text { discharge }\end{array}$ & $\begin{array}{l}\text { Follow-up } \\
\text { period } \\
\text { (days), MRI } \\
\text { evaluation } \\
\end{array}$ \\
\hline 1 & $69, \mathrm{M}$ & $\mathrm{V}$ & $\begin{array}{l}\text { distal } \\
\text { to PICA }\end{array}$ & extradural & $\begin{array}{l}\text { internal } \\
\text { endovascular } \\
\text { trapping }\end{array}$ & none & 2 & 3347 , good \\
\hline 2 & $56, \mathrm{M}$ & V & $\begin{array}{l}\text { PICA } \\
\text { involved }\end{array}$ & intradural & $\begin{array}{l}\text { proximal } \\
\text { endovascular } \\
\text { occlusion }\end{array}$ & rebleeding & 5 & 141, good \\
\hline 3 & $53, \mathrm{M}$ & II & $\begin{array}{l}\text { distal } \\
\text { to PICA }\end{array}$ & intradural & $\begin{array}{l}\text { internal } \\
\text { endovascular } \\
\text { trapping }\end{array}$ & recanalization & 1 & 1400, good \\
\hline 4 & $50, \mathrm{M}$ & $\mathrm{V}$ & non-PICA & $\begin{array}{l}\text { ipsilateral } \\
\text { AICA-PICA }\end{array}$ & $\begin{array}{l}\text { internal } \\
\text { endovascular } \\
\text { trapping }\end{array}$ & none & 6 & no \\
\hline 5 & $49, \mathrm{M}$ & IV & $\begin{array}{l}\text { distal } \\
\text { to PICA }\end{array}$ & intradural & $\begin{array}{l}\text { internal } \\
\text { endovascular } \\
\text { trapping }\end{array}$ & none & 2 & 1459, good \\
\hline 6 & $43, \mathrm{M}$ & $\mathrm{V}$ & $\begin{array}{l}\text { distal } \\
\text { to PICA }\end{array}$ & extradural & $\begin{array}{l}\text { internal } \\
\text { endovascular } \\
\text { trapping }\end{array}$ & none & 6 & no \\
\hline 7 & $61, \mathrm{M}$ & III & $\begin{array}{l}\text { distal } \\
\text { to PICA }\end{array}$ & intradural & $\begin{array}{l}\text { internal } \\
\text { endovascular } \\
\text { trapping }\end{array}$ & $\begin{array}{l}\text { medullary } \\
\text { infarction }\end{array}$ & 2 & 196, good \\
\hline 8 & $64, \mathrm{M}$ & $\mathrm{V}$ & $\begin{array}{l}\text { distal } \\
\text { to PICA }\end{array}$ & intradural & $\begin{array}{l}\text { internal } \\
\text { endovascular } \\
\text { trapping }\end{array}$ & rebleeding & 6 & no \\
\hline 9 & $69, \mathrm{M}$ & III & $\begin{array}{l}\text { distal } \\
\text { to PICA }\end{array}$ & intradural & $\begin{array}{l}\text { internal } \\
\text { endovascular } \\
\text { trapping }\end{array}$ & none & 2 & 633 , good \\
\hline 10 & $59, \mathrm{~F}$ & II & non-PICA & $\begin{array}{l}\text { ipsilateral } \\
\text { AICA-PICA }\end{array}$ & $\begin{array}{l}\text { internal } \\
\text { endovascular } \\
\text { trapping } \\
\text { using } \\
\text { pull-through } \\
\text { technique }\end{array}$ & $\begin{array}{l}\text { medullary } \\
\text { infarction }\end{array}$ & 3 & 224 , good \\
\hline 11 & $45, \mathrm{M}$ & III & non-PICA & $\begin{array}{l}\text { bilateral } \\
\text { AICA-PICA }\end{array}$ & $\begin{array}{l}\text { internal } \\
\text { endovascular } \\
\text { trapping }\end{array}$ & $\begin{array}{l}\text { medullary } \\
\text { infarction }\end{array}$ & 4 & 538, good \\
\hline \multirow[t]{2}{*}{12} & $57, \mathrm{M}$ & $\mathrm{V}$ & $\begin{array}{l}\text { PICA } \\
\text { involved }\end{array}$ & intradural & $\begin{array}{l}\text { proximal } \\
\text { endovascular } \\
\text { occlusion }\end{array}$ & $\begin{array}{l}\text { asymptomatic } \\
\text { occlusion }\end{array}$ & 1 & 345 , good \\
\hline & & & & & $\begin{array}{l}\text { OA-PICA } \\
\text { anastomosis } \\
\text { and surgical } \\
\text { trapping }\end{array}$ & of the bypass & & \\
\hline 13 & $61, \mathrm{~F}$ & I & $\begin{array}{l}\text { distal } \\
\text { to PICA }\end{array}$ & intradural & $\begin{array}{l}\text { internal } \\
\text { endovascular } \\
\text { trapping }\end{array}$ & $\begin{array}{l}\text { cerebellar } \\
\text { infarction }\end{array}$ & 1 & 212, good \\
\hline 14 & $52, \mathrm{M}$ & IV & $\begin{array}{l}\text { distal } \\
\text { to PICA }\end{array}$ & intradural & $\begin{array}{l}\text { internal } \\
\text { endovascular } \\
\text { trapping }\end{array}$ & none & 0 & 200 , good \\
\hline
\end{tabular}

stage developed asymptomatic occlusion of the bypass one month after bypass surgery. Although there is a lower risk of medullary infarc- tion in ipsilateral AICA-PICA type and VADA located non-PICA type, one of three patients with medullary infarction was of this type. The 

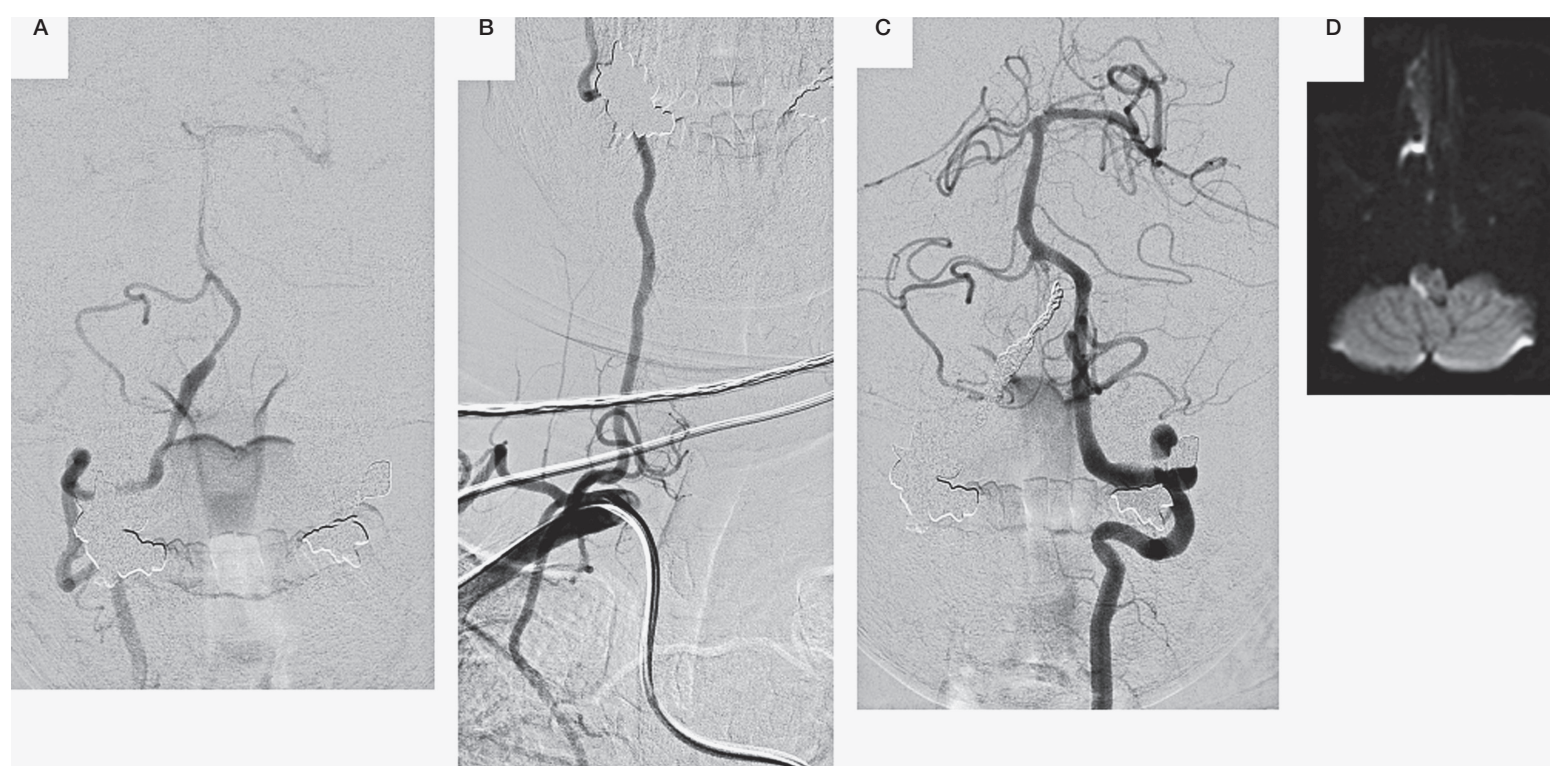

Figure 3 A) DSA revealed right VADA (ipsilateral AICA-PICA type and VADA located non-PICA type). B) The patient underwent the approach using the pull-through technique of guidewire placement between the femoral and brachial arteries, and the guiding catheter was introduced into subclavian artery. C) The final angiographic study showed sufficient contralateral flow to the basilar artery. D) MR diffusion-weighted imaging revealed a right lateral medullary infarction.

patient underwent the approach using the pullthrough technique of guidewire placement between the femoral artery and brachial artery, and the guiding catheter was introduced to the subclavian artery because of high-grade arteriosclerosis. There was a possibility of cerebral embolism of medullary infarction in this case.

The modified Rankin scales on discharge were grade $0-2$ in eight patients, grade $3-5$ in three patients, and grade 6 in three patients. After discharge, nine patients underwent clinical follow-up over a mean period of 26.3 months (range: 4.7-38.6 months). During the follow-up period, no rebleeding was observed, and MRI evaluations did not demonstrate any ischemic lesions or recanalization related to the VADA or treatment.

\section{Representative Cases}

Case 1. A 56-year-old man (patient 2 in Table 1) was admitted with severe headache and loss of consciousness. MRI showed diffuse subarachnoid hemorrhage and left VADA. DSA revealed left VADA involving the PICA origin (Figure 1A). He developed rebleeding during the endovascular procedure, and proximal occlusion was performed (Figure 1B). After the procedure, there was no rebleeding, but severe vasospasm developed (Figure 1C). Modified Rankin scale on discharge was 5, and he required long-term rehabilitation.

Case 2. A 57-year-old man (patient 12 in Table 1) was admitted with disturbance of consciousness. CT showed diffuse subarachnoid hemorrhage. CTA and DSA revealed right VADA involving the PICA origin (Figure 2A). Proximal occlusion was performed (Figure 2B). OA-PICA anastomosis and surgical trapping were performed successfully 20 days after onset (Figure 2C). However, he developed asymptomatic occlusion of the bypass one month after bypass surgery (Figure 2D).

Case 3. A 59-year-old woman (patient 10 in Table 1) was admitted with disturbance of consciousness. CT showed subarachnoid hemorrhage predominantly localized in the posterior fossa. CTA and DSA (Figure 3A) revealed right VADA (ipsilateral AICA-PICA type and VADA located non-PICA type). Subsequently, internal endovascular trapping was performed successfully using the pull-through technique (Figure 3B). The final angiographic study showed sufficient contralateral flow to the basilar artery (Figure 3C). Lateral medullary syndrome became apparent, and diffusion-weighted imaging performed on postoperative day 2 revealed a right lateral medullary infarction (Figure 3D). 


\section{Discussion}

Twelve patients underwent internal endovascular trapping, one underwent proximal endovascular occlusion alone, and one underwent proximal endovascular occlusion in the acute stage and occipital artery-PICA anastomosis and surgical trapping in the chronic stage. The types of VADA based on their location relative to the ipsilateral PICA were distal, PICA-involved, and non-PICA in nine, two, and three patients, respectively. The types of PICA based on their development and location were bilateral AICA-PICA, ipsilateral AICA-PICA, extradural, and intradural type in one, two, two, and nine patients, respectively. Two patients with high anatomical risk developed medullary infarction, but their outcomes were better than those in other reports. The modified Rankin scale indicated grades $0-2,3-5$, and 6 in eight, three, and three patients, respectively.

VADAs are generally categorized into bleeding and non-bleeding types. The rebleeding rate is very high $(30 \%-70 \%)^{1,13}$ with a mortality rate of $46 \%$ in patients with bleeding type of VADA 14-16. Therefore, patients with the bleeding type should be treated as soon as possible. Endovascular treatment is thought to be more advantageous than craniotomy with clipping or trapping because patients can undergo curative treatment following diagnostic angiography. The main treatment options for endovascular parent artery occlusion are internal trapping and proximal occlusion. The strategy for endovascular treatment of ruptured VADAs depends on the location of the VADA relative to the ipsilateral PICA. Proximal occlusion is technically simpler and easier than internal trapping. A previous report indicated that proximal occlusion carries a risk of post-treatment rebleeding because of residual blood flow into the dissected VA ${ }^{17}$. However, in our series and in another report ${ }^{18}$, no patients showed rebleeding after proximal occlusion. Internal trapping completely excludes the dissected VA from the circulation, while two patients in our series underwent proximal occlusion because of the PICA-involved type.

Stent-assisted coil embolization and bypass surgery have been reported in the literature ${ }^{19-}$ ${ }^{21}$, especially cases in which internal trapping is contraindicated. The benefit of stent-assisted coil embolization is preservation of the dissected VA. However, it carries a risk of hemorrhagic complications because of the need for an- tiplatelet therapy. The treatment strategy for the PICA-involved type remains controversial because rupture near the ipsilateral PICA is associated with a risk of ischemic events. There are a few treatment options: proximal occlusion, internal trapping with or without OA-PI$\mathrm{CA}$ anastomosis, flow-diverting stent, and stent-assisted coil embolization. Iihara et al. proposed a stage-dependent treatment strategy for PICA-involved type ruptured VADA ${ }^{4}$. In the acute stage, endovascular proximal occlusion is performed to decrease the risk of rebleeding. In the chronic stage, balloon test occlusion is performed to evaluate tolerance for ipsilateral PICA occlusion. If the patient can tolerate ipsilateral PICA occlusion, internal trapping without bypass surgery is done. If the patient cannot tolerate this procedure, clip ligation of the origin of the ipsilateral PICA with OA-PICA anastomosis is done. However, several authors have indicated that occlusion of the ipsilateral PICA is not clinically problematic because of sufficient collateral circulation 3,22. Kim et al. reported VA to PICA stent placement and coil embolization for PICA-involved type ruptured VADA, and midterm follow-up angiography revealed that flow of the PICA was patent without stenosis or occlusion ${ }^{20}$. This is close to an ideal method. Furthermore, VADA of PICA-involved type will be treated effectively and safely with the development of more feasible and smaller caliber stents. The Japanese medical insurance system does not authorize the use of flow-diverter stents, and has only authorized intracranial stents (e.g., Enterprise, Neuroform) for saccular large unruptured aneurysms with a wide neck. When the ethics committee of our hospital approves the off-label use of stents in dissecting aneurysms, we will use these stents especially on the dominant side of the ipsilateral vertebral artery or PICA-involved type.

Endovascularly treated ruptured VADAs have been reported to show good recovery in $47 \%-66.7 \%$ of cases, moderate disability in $11.1 \%-29.4 \%$, and death in $8.0 \%-23.8 \%^{7,9,10,18}$. Our results are similar to these reports. It is well known that patients with high-grade SAH have a poor prognosis. In our study and in another report, patients with high-grade SAH showed comparatively better recovery than initially estimated. Therefore, aggressive treatment should be considered for patients with VADA and high-grade SAH. Taha et al. reported encountering complications in the endovas- 
cular treatment of ruptured VADAs in $16 \%$ of patients (angiographic recanalization in $8.0 \%$ and ischemic events in $8.0 \%)^{10}$. In our series, complications of endovascular treatment in ruptured VADAs were angiographic recanalization in $7.1 \%$ of cases and ischemic events in $29 \%$.

Postoperative medullary infarctions have been reported as unresolved complications of internal coil trapping ${ }^{3-5}$. Endo et al. reported that the occurrence of postoperative medullary infarction was correlated with unfavorable outcome at six-month follow-up ${ }^{23}$. The use of coils to trap the dissection can lead to occlusion of the perforating artery arising from the VA or PICA, thus resulting in the formation of a medullary infarction $3,4,23$. Lateral medullary syndrome occurred in $5.6 \%-47 \%$ of cases of ruptured VADA after endovascular treatment ${ }^{3-5,23}$. There may be unidentified cases of postoperative medullary infarction because it is difficult to recognize symptoms of brainstem ischemia during the acute stage of SAH. In our series, postoperative medullary infarction on MRI occurred in $3 / 14$ cases $(21.4 \%)$, but the symptoms were improved in all three cases at six-month follow-up. Anatomical studies have shown that perforating vessels arising from the PICA or proximal VA are responsible for vascularization of the posterior surface of the medulla oblongata. A lateral medullary infarction may occur if the artery is compromised ${ }^{11}$. The anatomical variations of these perforators largely depend on the development of the PICA and the location of the PICA origin ${ }^{11}$. However, one case of postoperative medullary infarction in our series had a lower risk of medullary infarction in ipsilateral AICA-PICA type and VADA located non-PICA type, and we felt that there was a possibility of cerebral embolism. The anatomical location and development of PICA may be predicted by complication with postoperative medullary infarction. Endo et al. reported that trapping of the longer segments of the intracranial VA was associated with obliteration of more perforators that supply the medulla oblongata ${ }^{23}$. In our series, the length of the trapped VADA by coils was not measured.
According to the results of our study after discharge, nine patients underwent clinical follow-up over a mean period of 26.3 months (range: 4.7-38.6 months). During the follow-up period, no rebleeding was observed, and MRI evaluations did not demonstrate further ischemic lesions or recanalization related to the VADA or treatment. Kashiwazaki et al. reported the long-term (mean 55.6 months) outcome of ruptured and unruptured VADAs (exclusion criteria: Hunt and Kosnik grade 5, PICA-involved type, and hypoplasia of contralateral VA), and their study confirmed that endovascular internal trapping is a stable and durable treatment for closure of VADAs ${ }^{24}$. With regard to preventing vasospasm in our previous study 25 , the incidence of vasospasm as observed on angiography, symptomatic vasospasm, and new cerebral infarction due to vasospasm as observed on CT were apparently lower in the cilostazol and atorvastatin group than in the control group. Cilostazol and atorvastatin may prevent vasospasm, but did not improve the final clinical outcome.

Several limitations of this study must be noted. The small sample size limited our ability to evaluate the outcome, treatment strategy, and complications. As our study involved retrospective data acquisition, a prospective study with a more rigorous technical and follow-up strategy is warranted. Decisions regarding treatment indications may have resulted in inclusion bias. Prospective randomized trials with long periods of follow-up are needed to establish the best treatment strategy for these patients.

\section{Conclusions}

A good outcome of ruptured VADA treatment using internal endovascular trapping is often obtained, except with the PICA-involved type, even with high-grade subarachnoid hemorrhage. Treatment of the PICA-involved type is controversial. The anatomical location and development of PICA may be predicted by complications with postoperative medullary infarction. 


\section{References}

1 Mizutani T, Aruga T, KirinoT, et al. Recurrent subarachnoid hemorrhage from untreated ruptured vertebrobasilar dissecting aneurysms. Neurosurgery. 1995; 36 (5): 905-913. doi: 10.1227/00006123-199505000-00003.

2 Yamaura A, Watanabe Y, Saeki N, et al. Dissecting aneurysms of the intracranial vertebral artery. J Neurosurg. 1990; 72 (2):183-188. doi:10.3171/jns.1990.72.2.0183.

3 Hamada J, Kai Y, Morioka M, et al. Multimodal treatment of ruptured dissecting aneurysms of the vertebral artery during the acute stage. J Neurosurg. 2003; 99 (6): 960-966. doi: 10.3171/jns.2003.99.6.0960

4 Iihara K, Sakai N, Murao K, et al. Dissecting aneurysms of the vertebral artery: a management strategy. J Neurosurg. 2002; 97 (2):259-267. doi:10.3171/jns.2002.97.2.0259.

5 Lee JM, Kim TS, Joo SP, et al. Endovascular treatment of ruptured dissecting vertebral artery aneurysms long-term follow-up results, benefits of early embolization, and predictors of outcome. Acta Neurochir (Wien). 2010; 152 (9): 1455-1465. doi: 10.1007/s00701-010-0683-9.

6 Peluso JP, van Rooij WJ, Sluzewski M, et al. Endovascular treatment of symptomatic intradural vertebral dissecting aneurysms. Am J Neuroradiol. 2008; 29 (1): 102106. doi: 10.3174/ajnr.A0771.

7 Rabinov JD, Hellinger FR, Morris PP, et al. Endovascular management of vertebrobasilar dissecting aneurysms. Am J Neuroradiol. 2003; 24 (7): 1421-1428.

8 Sugiu K, Tokunaga K, Watanabe K, et al. Emergent endovascular treatment of ruptured vertebral artery dissecting aneurysms. Neuroradiology. 2005; 47 (2): 158164. doi: $10.1007 / \mathrm{s} 00234-005-1341-4$.

9 Kurata A, Ohmomo T, Miyasaka Y, et al. Coil embolization for the treatment of ruptured dissecting vertebral aneurysms. Am J Neuroradiol. 2001; 22 (1): 11-18.

10 Taha M, Sakaida H, Asakura F, et al. Endovascular management of vertebral artery dissecting aneurysms: review of 25 patients. Turk Neurosurg. 2010; 20 (2): 126135. doi: 10.5137/1019-5149.JTN.2790-09.0.

11 Mercier PH, Brassier G, Fournier HD, et al. Vascular microanatomy of the pontomedullary junction, posterior inferior cerebellar arteries, and the lateral spinal arteries. Interv Neuroradiol. 2008; 14 (1): 49-58.

12 Kim BM, Kim SH, Kim DI, et al. Outcomes and prognostic factors of intracranial unruptured vertebrobasilar artery dissection. Neurology. 2011; 76 (20): 1735-1741. doi: 10.1212/WNL.0b013e31821a7d94.

13 Aoki N, Sakai T. Rebleeding from intracranial dissecting aneurysm in the vertebral artery. Stroke. 1990; 21 (11): 1628-1631. doi: 10.1161/01.STR.21.11.1628.

14 Andoh T, Shirakami S, Nakashima T, et al. Clinical analysis of a series of vertebral aneurysm cases. Neurosurgery. 1992; 31 (6): 987-993. doi: 10.1227/00006123199212000-00001.

15 Dohi K, Kubota M, Hamada H, et al. Compression of medulla oblongata by the dissecting aneurysm of the vertebral artery 7 years after its rupture: case report. No Shinkei Geka. 1994; 22 (11): 1067-1070.

16 Kamiyama H, Nomura M, Abe H, et al. Diagnosis of intracranial dissecting aneurysms. Surg Cereb Stroke. 1990; 18: 50-56.

17 Yasui T, Komiyama M, Nishikawa M, et al. Subarachnoid hemorrhage from vertebral artery dissecting aneurysms involving the origin of the posteroinferior cerebellar artery: report of two cases and review of the literature. Neurosurgery. 2000; 46 (1): 196-200. doi: 10.1097/00006123-200001000-00038.

18 Nonaka S, Oishi H, Suga Y, et al. Endovascular parent artery occlusion of ruptured vertebral artery dissecting aneurysms. JNET. 2012, 6 (2): 98-104. doi: 10.5797/ jnet.6.98.
19 Chung J, Kim BS, Lee D, et al. Vertebral artery occlusion with vertebral artery-to-posterior inferior cerebellar artery stenting for preservation of the PICA in treating ruptured vertebral artery dissection. Acta Neurochir (Wien). 2010; 152 (9): 1489-1492. doi: 10.1007/s00701010-0725-3.

20 Kim MJ, Chung J, Kim SL, et al. Stenting from the vertebral artery to the posterior inferior cerebellar artery. Am J Neuroradiol. 2012; 33: 348-352. doi: 10.3174/ajnr. A2741.

21 Sadato A, Maeda S, Hayakawa M, et al. Endovascular treatment of vertebral artery dissection using stents and coils: its pitfall and technical considerations. Minim Invasive Neurosurg. 2010; 53 (5-6): 243-249. doi: 10.1055/s0030-1269873.

22 Ono J, Hirai S, Kobayashi E, et al. Early management of ruptured arterial dissection in the vertebrobasilar system: analysis of the cases with subsequent rupture. Neurosurg Emerg. 2003; 8: 30-34.

23 Endo H, Matsumoto Y, Kondo R, et al. Medullary infarction as a poor prognostic factor after internal coil trapping of a ruptured vertebral artery dissection. J Neurosurg. 2013;118(1):131-139.doi:10.3171/2012.9.JNS 12566.

24 Kashiwazaki D, Ushikoshi S, Asano T, et al. Long-term clinical and radiological results of endovascular internal trapping in vertebral artery dissection. Neuroradiology. 2013; 55 (2): 201-206. doi: 10.1007/s00234-012-1114-9.

25 Hamasaki O, Ikawa F, Hidaka T, et al. Usefulness of Cilostazol and Atorvastatin for preventing vasospasm after subarachnoid hemorrhage. Surg Cereb Stroke (Jpn). 2013; 41 (5): 339-342. doi: 10.2335/scs.41.339.

Osamu Hamasaki, MD

Department of Neurosurgery

Shimane Prefectural Central Hospital

4-1-1 Himebara, Izumo

Shimane 693-8555

Japan

Tel.: +81-853-22-5111

Fax: +81-853-21-2975

E-mail: ohamasa@orange.ocn.ne.jp 